\title{
A DANÇA NO CONTEXTO DA EDUCAÇÃO INFANTIL: POSSIBILIDADES DE EXPRESSÃO ARTÍSTICA E CRÍTICA PARA CRIANÇAS*
}

\author{
Mônica Caldas Ehrenberg ${ }^{1}$
}

\section{Introdução}

O capítulo que segue abordará questões relativas à dança, em específico para o segmento da educação infantil. Neste capítulo, buscaremos vislumbrar as possibilidades da dança como uma prática corporal que representa formas de expressão criadas pelo homem e que são dialógicas com o mundo. Em termos metodológicos, trata-se aqui de uma pesquisa bibliográfica sobre a temática elencada.

Não será tratado neste texto o entendimento restrito de expressão corporal que identifica que este seja um conhecimento (conteúdo) das aulas de dança como alguns autores propõem, mas sim num entendimento que a expressão corporal possa ser um conteúdo em si, que possui sua própria identidade como mensagem gestual e que a dança, sendo um dos conhecimentos da Educação Física se apropria de tal.

Vale ressaltar que o texto que segue se apropria do avanço das discussões e da parceria estabelecida tanto pela educação infantil quanto pela Educação Física, como possíveis problematizadoras dos textos da linguagem corporal, e a presença da pedagoga como professora responsável por tal engajamento. Especificamos a presença das professoras pedagogas, tendo em vista que nem sempre o professor especialista em Educação Física atua com as crianças da educação infantil, ficando a cargo da responsável pela sala assumir a tarefa de realização das práticas corporais.

Confesso aqui que não me assombra a ideia de termos a professora de sala atuando com as práticas corporais, até porque reconheço que crianças pequenas precisam estabelecer vínculos e o fato de terem muitos professores nem sempre colabora para a segurança e tranquilidade afetiva das crianças. Não temos um "dono" para trabalhar o corpo na

\footnotetext{
* 10.29388/978-65-86678-46-8-0-f.49-60

1 Professora da Faculdade de Educação da USP. Coordenadora do Grupo de Estudos e Pesquisas em Gesto, Expressão e Educação (GEPGEE) da USP. Vice líder do Grupo de Ginástica para Todos - Gymnusp. E-mail: monica.ce@,usp.br
} 
escola. Especialmente tratando-se de crianças da educação infantil, sua corporalidade latente exige que todos os professores estejam atentos e disponíveis para o trabalho. No entanto, ressalto a importância das professoras de sala estar bem formadas, capacitadas e confiantes para a realização dos trabalhos, podendo sempre estar assessoradas por professores específicos da Educação Física.

Em pesquisa anterior Ehrenberg (2014) já havia enfatizado o fato da Educação Física estar inserida no universo da educação infantil a partir da Lei de Diretrizes e Bases da Educação Brasileira, porém naquele momento já reconhecia:

Consideramos um grande avanço para a área da Educação Física tal inserção no currículo da Educação Infantil, mas reconhecemos a necessidade de estudos específicos para garantir uma proposta de qualidade e condizente com as expectativas de educação para a criança desse segmento (EHRENBERG, 2014, p. 183).

A legislação ainda não é suficiente para garantir essa qualidade esperada e nem tampouco especifica a presença do professor especialista. Nesse sentido, a garantia do direito da pequena infância a uma educação de qualidade, centrada em suas necessidades e cultura, parece ainda distante. Diante disso, imaginamos que a Educação Física, inserida no referido segmento, também ainda necessita de muito estudo para avançar e para se efetivar.

Para pensar nas questões da expressividade apoio-me nas palavras de Gomes-da-Silva; Sant'Agostino e Betti (2005) por reconhecer que a expressão corporal como linguagem da Educação Física pode ser abordada em si mesma, e não necessariamente vinculada a outras manifestações da cultura corporal como jogos, esportes, ginásticas, danças. No entanto, reconhecemos que, frequentemente, a expressão corporal limita-se num repetir de movimentos padronizados e hegemonicamente determinados que restringem o entendimento, não possibilitando assim que o corpo realmente se expresse, mas sim que o corpo reproduza, copie movimentos secos, sem muito sentido para o aluno.

Quando a linguagem corporal é reconhecida como modo de expressão e comunicação, torna-se necessário rever as práticas educativas da Educação Física. É urgente compreender o espaço pedagógico do componente como lócus de apropriação da variedade de formas pelas quais a cultura lúdica se expressa. Ou seja, as atividades de ensino precisam contribuir para alargar a compreensão 
que as crianças possuem acerca da realidade em que vivem e para abrir caminhos para uma participação mais intensa no mundo, participação que se faz pela interpretação, criação e transformação da sua linguagem corporal original e pela interpretação e ressignificação das diversas linguagens corporais manifestas pelos outros grupos que habitam a sociedade (NEIRA, 2009, p. 85).

Torna-se importante explicitar as concepções que sustentam este escrito para que se tenha clareza sobre as sugestões e proposições que aqui serão expostas. Desta forma, ressalto o entendimento que se tem acerca de criança da educação infantil. Partiremos do entendimento que cabe à escola de educação infantil, elaborar currículos e práticas pedagógicas que tomem como pressupostos a condição de cada criança como sujeito cultural em constante construção, produção e reconstrução.

As crianças produzem cultura e são produzidas na cultura em que se inserem e que lhes é contemporânea. $\mathrm{O}$ percurso de vida de cada criança até seu ingresso na Educação Infantil é profundamente marcado, ao menos na maioria dos casos, pelo seu espaço familiar e doméstico. Nele, um determinado conjunto de conhecimentos é socializado e certas interpretações sobre o mundo são acessadas (NEIRA, 2008, p. 58-59).

As danças, as lutas, os jogos, os esportes e outras manifestações que são expressas pela motricidade humana são denominadas de cultura corporal, ou cultura corporal de movimento (COLETIVO DE AUTORES, 1992). Dessa forma, partiremos do entendimento de que a cultura corporal é o objeto de estudo da Educação Física na escola. Sendo assim, a dança, como as demais práticas corporais, representam formas de expressão criadas pelo homem e que são passíveis de diálogos com o mundo e, justamente esses diálogos se materializam como linguagem corporal infantil.

De acordo com Sborquia e Gallardo (2006) podemos compreender a cultura corporal como uma linguagem que pode ser socializada pelas crianças na escola e, portanto torna-se impossível compreender sua realidade natural e social como contraditórias, mas sim como complementares.

Tendo apresentado os pressupostos que ancoram tal artigo, partimos para a especificidade do mesmo em que buscamos oportunizar aproximações da dança no contexto da educação infantil. 


\section{A Dança no contexto escolar}

Considera-se importante reconhecer que as práticas corporais a serem vivenciadas na escola precisam estar comprometidas com a instituição escolar, integradas a proposta pedagógica e alinhadas ao entendimento legal do segmento de ensino a ser trabalhado. Desta forma, a repetição de movimentos estereotipados e a cópia de danças previamente preparadas pelos professores e copiadas pelos alunos não correspondem à concepção que acreditamos estar inserida na escola, já que essa forma privilegia (se é que realmente privilegia algo) o domínio de técnicas específicas, em detrimento da contextualização, comprometendo a formação humana e aspectos educativos esperados pela escola.

A dança, compreendida como expressão humana e, portanto, forma de comunicação não deveria ter o gesto como limitador e sim como algo que transcende a visão utilitarista da técnica específica e congrega uma dimensão singular e comunicativa. As formas prontas, padronizadas, associadas comumente pela mídia, quase sempre chegam desprovidas de história e contextualização, dificultando assim sua compreensão e estimulando mera reprodução, algo que não congrega os valores e intencionalidades de uma instituição de ensino.

"Há que se fugir da tentação de qualificar os gestos produzidos pelas crianças como certos ou errados, de focalizar a quantidade ou a melhora do rendimento." (NEIRA, 2014, p. 67)

A dança inserida no contexto escolar deve "[...] transformar os alunos em melhores pensadores de arte, melhores consumidores, espectadores, almas". (MARQUES, 2001, p.36). O objetivo, estando inseridos no contexto escolar, é fomentar o diálogo por meio das danças, concebidas como produtos culturais. Ampliando o enfoque da Educação Física escolar, entendemos que a dança, como outras manifestações da cultura corporal, possa ser capaz de inserir o aluno no mundo em que vive de forma crítica, percebendo-se como produtor de cultura, reconhecendo-se como agente de possível transformação; mas, para tal, é necessário não apenas contemplar estes conteúdos como mero espectador, para não dizer repetidor, e sim identificá-los, vivenciá-los e interpretá-los corporalmente.

Sem dúvida, existem várias formas culturais de compreendermos a dança-manifestações construídas ao longo dos tempos e específicas de cada local - mas não existe sentido em estudar tais manifestações na escola se elas estiverem desvinculadas de seu contexto social, político, histórico e cultural (EHRENBERG; PÉREZ GALLARDO, 2005). Se sua 
origem parece ter sido na religião, a dança e o corpo que materializa essa dança, assumiram outras influências com o passar do tempo. Relações sociais, políticas, econômicas foram expressas por danças como os balés da corte do século XVI, na França.

Manifestações contemporâneas como hip hop e street dance também desvelam importantes chaves do comportamento e da cultura urbanos. O corpo adquire significado por meio da experiência social e cultural do indivíduo em seu grupo, tornando-se discurso a respeito da sociedade, passível de leituras diferenciadas por atores sociais distintos (SIQUEIRA, 2006, p. 42).

De fato, a dança reflete os movimentos sociais, podendo desvelar sentidos e significados históricos e contemporâneos. Mas, construir e compreender esses movimentos que contam, falam e que nos transportam historicamente não é uma tarefa simples. É necessário sabermos o que queremos contar. É necessário inserirmo-nos no contexto a ser desvelado.

A dança vivenciada como forma de expressão do corpo comunica valores, expressa sentimentos, cultua subjetividade e significados. Nesse sentido, a dança realmente pode ser entendida como uma forma de linguagem, como um conjunto de gestos. Ao reconhecer a linguagem corporal como forma de expressão, torna-se necessário rever as práticas educativas da Educação Física e a dança como conhecimento a ser tratado por ela.

Fernandes e Bratifische (2014) corroboram nossa afirmação e ressaltam que o trabalho da dança na escola não deve ter o foco no domínio de uma técnica específica, ou estilo de dança. As autoras especificam que o estudo da dança no contexto escolar deve estar centrado no estudo e na vivência dos gestos, na leitura e na interpretação de significados. De acordo com as autoras é importante reconhecer que a dança é uma linguagem artística que possibilita o desenvolvimento da expressividade poética, de sentimentos e de criticidade a partir do entendimento das diferentes visões de mundo. Mas, e as crianças da educação infantil? Seria possível trabalhar a dança com esses aspectos com crianças pequenas? Seriam as crianças capazes de se expressarem e se apropriarem de um contexto crítico trazido pela dança? Ou para crianças pequenas seria necessário ficarmos apenas pautados pela reprodução de coreografias previamente elaboradas? 


\section{A dança para crianças da educação infantil}

Para tentar responder as questões elencadas anteriormente será necessário reconhecer que as especificidades da educação infantil são muitas. A dança frequentemente está presente neste contexto, porém raramente pautada pelos pressupostos já anunciados neste texto. A repetição, a cópia estilizada de movimentos são as representações mais encontradas e chamadas por dança na educação infantil, conforme já nos apontou a pesquisa de Ehrenberg e Perez Gallardo (2005).

Ainda, na tentativa de evidenciar a importância da expressão corporal para crianças, utilizo-me das palavras de Ayoub (2001, p.56-57. Grifo da autora):

Pensando na "criança como ponto de partida na educação infantil", a expressão corporal caracteriza-se como uma das linguagens fundamentais a serem trabalhadas na infância. A riqueza de possibilidades da linguagem corporal revela um universo a ser vivenciado, conhecido e desfrutado com prazer e alegria.

Reforço tal questão tendo em vista que comumente as experiências e experimentações corporais na educação infantil limitam-se a dois pólos distintos e que, isoladamente, consideramos equivocados, são eles: os "momentos livres", sem intenção formativa; e os momentos de reprodução de movimentos estereotipados e mecânicos, com intenção formativa que não possibilitam uma real compreensão de cultura corporal. Ressalto que considero esses dois pólos equivocados se trabalhados de maneira única, estanque e de maneira repetida e contínua, afinal a importância de momentos "livres", não dirigidos, para crianças da educação infantil é de suma importância e relevância, bem como usar modelos já definidos previamente também pode ser uma das possibilidades de ensino. Sendo assim, ambas as formas têm o seu valor, porém habitualmente encontramos apenas uma ou apenas outra destas maneiras de atuar com a dança para crianças. Ademais, conforme já explicitado no texto, tratando-se do contexto escolar não podemos desconsiderar especificidades e encaminhamentos necessários a fim de contribuir com a formação de crianças atentas e ativas no grupo social em que vivem.

Tais características (os chamados dois polos) não colaboram para que o espaço da linguagem corporal na escola seja efetivado, sucumbindo a Educação Física a uma visão disciplinadora que apenas contribui para domesticar o corpo ou para implicitamente dizer que a Educação 
Física nada tem a ensinar, é apenas um momento de lazer descompromissado.

As manifestações da dança inseridas no contexto da educação infantil refletem claramente tais apontamentos.

Comumente as danças aparecem nos momentos festivos da escola sem qualquer contextualização nem tampouco com oportunidade de exprimir sentidos e significados. O que realmente idealizamos é que a dança seja entendida como uma forma de comunicação e expressão. Visualizamos uma dança em que seja possível que os alunos descubram suas possibilidades corporais e consigam manifestar desejos, sentimentos, expressar conhecimentos. Não acreditamos em práticas corporais nas aulas de Educação Física com objetivos centrados em si mesmo, ao contrário, prezamos por uma apropriação crítica da manifestação vivenciada.

Não propomos aqui que os conteúdos percam sua especificidade, mas que não fiquem focados em objetivos centrados em si próprios; afinal, seja qual for o conhecimento tratado na escola, deverá ter, entre seus objetivos, a educação de valores, normas, apropriação da realidade e grupo social enfim, a formação humana crítica, afinal estes são alguns dos papéis sociais da escola.

A dança reflete movimentos sociais, podendo desvelar sentidos e significados históricos e contemporâneos. Mas, construir e compreender esses movimentos que contam, falam e que nos transportam historicamente não é uma tarefa simples. É necessário sabermos o que queremos contar. É necessário inserirmo-nos no contexto a ser desvelado.

Seriam as crianças realmente capazes de terem apropriação da dança com esse contexto?

Para discutirmos um pouco sobre essas questões devemos reconhecer que as crianças das nossas escolas de hoje possuem um rico e vasto conhecimento de sua cultura local, de seus grupos de pertencimento. Elas se identificam nesse universo particular que, sem dúvida, está entrelaçado a significados que elas mesmas dão.

Em pesquisa realizada anteriormente ${ }^{2}$ pudemos perceber a riqueza de possibilidades ocorrida com o conhecimento da dança trabalhada com alunos de educação infantil. Ficou muito evidente que as crianças em idade pré-escolar ainda não estão limitadas a regras sociais, não estão

${ }^{2}$ EHRENBERG, Mônica Caldas. A dança como conhecimento a ser tratado pela

Educação Física escolar: aproximações entre formação e atuação profissional. 2003. 129 fls. Dissertação Mestrado. Faculdade Educação Física, Universidade Estadual de Campinas. 
tolhidas em suas manifestações. Elas têm alto poder de imaginação, além de serem facilmente motivadas e criarem com muita facilidade.

Sugerimos para crianças pequenas que a expressão corporal, bem como a descoberta dos fatores tempo, espaço e peso sejam conhecimentos abordados pelas aulas de dança no contexto da Educação Física. Lembrando que já foi exposto aqui, a possibilidade da expressão corporal ser um conteúdo por si só e não tendo a necessidade de estar inserida como conhecimento da dança.

Laban (1978) autor clássico dos estudos da dança, já sugeria estes fatores que dão qualidade ao movimento e ações corporais como primordiais à compreensão e significação do movimento humano, imprescindíveis para se dançar. Desde aquela época, esses fatores do movimento sugeridos por Laban tem sido fonte importante e muito reconhecida como possível de trabalhar a dança em diferentes contextos.

Deslocar-se de diferentes formas, em diferentes ritmos, ora "moles como geléia", ora "firmes e rígidos como robôs" permitem a descoberta das possibilidades corporais que serão utilizadas a todo o momento num trabalho de dança. Para as crianças da educação infantil, torna-se imprescindível tendo em vista a necessidade dos mesmos em se conhecerem, bem como conhecerem suas potencialidades, suas fragilidades, suas possibilidades corporais.

Ao princípio do tempo subtende-se o ritmo inerente em todas as coisas. O tempo pode ser entendido como a duração de um movimento ou de um espaço entre som e silêncio, seja natural ou construído.

O fator tempo indica em que tempo o movimento se produz. Ele pode ser lento, lentíssimo, rápido ou muito rápido. É um importante fator para que as crianças comecem a reconhecer seu tempo natural frente ao tempo construído da música. Não se espera que as crianças de educação infantil se movimentem no ritmo da música de forma controlada, mas que iniciem um processo de reconhecimento deste fator.

As brincadeiras e jogos recreativos podem ser aliados da dança como forma prazerosa de compreender o universo rítmico e o corpo em movimento, sendo assim os jogos e brincadeiras rítmicas são utilizados aqui como metodologia de ensino.

E possível experimentar e apresentar para as crianças vários tipos de ritmos e danças que podem ser classificados como mais lentos ou mais acelerados. Quais reconhecem e quais são desconhecidos? Será que identificam a origem de cada uma das danças apresentadas? 
E fundamental que o trabalho pedagógico com as danças passe pelo reconhecimento das diferenças existentes entre as crianças para, a partir delas e dos saberes culturais construídos fora dos muros escolares, desenvolver condições de equidade sociocultural (NEIRA, 2014, p. 72).

Torna-se importante apresentar as possibilidades das várias culturas de coabitam a nossa sociedade, além de ser possível problematizar questões de gênero, etnia, relações de poder, entre outras. A música pode ser forte aliada nesse processo de trabalho com a dança.

Outro fator apresentado por Laban (1978) é o espaço que se apresenta como o trajeto do movimento no espaço e como o mesmo se apresenta. Os movimentos poderão ter, ou não deslocamentos. É importante que as crianças sejam aguçadas a explorar o espaço de forma a reconhecer todas as possibilidades que o corpo possui para se deslocar, seja no espaço terrestre ou aéreo, por meio de saltos e suspensões. $\mathrm{O}$ espaço poderá se apresentar frente ao movimento de forma direta, com movimentos lineares, ou ainda de forma flexível, com movimentação ampla, arredondada.

Ainda pautados pelo fator espaço é possível que as crianças percebam e descubram a existência de danças mais contidas, com pequenos deslocamentos e outras em que o corpo precisa de espaço amplo em que os deslocamentos são amplos, alargados. Reconhecer também em quais espaços as diferentes manifestações de dança são vivenciadas e suas transformações ao longo dos tempos também pode ser bastante importante no reconhecimento de que há uma transformação social também na prática corporal da dança.

O último fator sugerido trata-se do Peso que se refere ao uso da força despendida para a ação. O movimento pode ser leve, suave, delicado ou ainda contrapor-se e apresentar-se de forma pesada, forte, firme. Muitas vezes a música nos parece "pedir" um determinado tipo de peso para movimentar-se nela, ou seja, quando ouvimos uma música melódica, tranquila é possível que reconheçamos uma intenção de movimentos leves, suaves. Tenha ou não estímulo sonoro é importante que os alunos percebam possibilidades diferentes de intenção de ação em cada movimento. É importante que percebam a possibilidade de variar a intenção dos movimentos.

Assim como nos fatores de movimento anteriormente citados, aqui para o fator peso, também podemos associar questões que não se limitem ao movimento por si só. Reconhecer danças mais suaves (leves) e 
danças mais fortes (pesadas) também faz parte do se apropriar criticamente do universo da dança. Reconhecer em quais espaços, sob quais objetivos cada tipo de dança se materializa pode oportunizar para as crianças uma descoberta acerca da vasta gama de tipos, estilos e performances da dança. Certamente as crianças descobrirão um universo amplo, rico e pertencentes a sua origem, sua história, seu grupo social, além de perceberem que seu grupo está inserido dentro de outros grupos maiores.

\section{Enfim, crianças pequenas dançando...}

E de suma importância, no contexto escolar, que a dança, bem como as demais práticas corporais, sejam tratadas de forma contextualizada, permitindo que as crianças se apropriem de seu contexto e sintamse partícipes do processo de criação e recriação dessas práticas.

$\mathrm{O}$ aprofundamento dos conhecimentos a respeito de uma dança será possível mediante a compreensão sócio histórica e política. Ė importante que as crianças conheçam a origem das danças, suas modificações e os seus significados, além de reconhecer que esses foram produzidos e passam por reproduções todo o tempo.

Não há limites e restrições, em relação às fontes de informações. Estudar e vivenciar uma dança da mídia, já conhecida pelas crianças, não é um problema e sim uma das maneiras de ressignificação deste conhecimento. O problema na verdade está em reproduzir esse contexto midiático, de forma descontextualizada, para ser meramente reproduzido pelas crianças.

As crianças, mesmo as pequenas da educação infantil, são capazes de estruturar tais conhecimentos, além de conhecer, ampliar e aprofundar os conhecimentos já pertencentes a elas.

Considerando as produções culturais das crianças podemos repensar o contexto escolar da educação infantil como um ambiente que não apenas institucionaliza a infância, que não apenas propõem que crianças copiem movimentos de forma descontextualizados, mas também formaliza e condiciona algumas vivências socialmente reconhecidas como importantes às crianças.

As práticas pedagógicas empregadas, no contexto da educação infantil, assim como a dança em específico, influenciam - mas, não determinam - as ações dos coletivos infantis, agregando elementos sociais que impactam suas formas de expressão, os significados e os sentidos permutados entre as crianças. Sendo assim, a dança no contexto da edu- 
cação infantil pode ser uma aliada ao entendimento de criança como produtora cultural.

Não se trata de considerar a dança como oportunizadora de apenas um gesto isoladamente, mas sua possível extensão significativa, interpretável, cuja potência comunicativa pode ser compreendida como atos de linguagem, que expressam formas de conhecimento e reflexão da criança acerca de suas experiências no mundo, com os outros e consigo.

\section{Referências}

AYOUB, Eliana. Reflexões sobre a Educação Física na Educação Infantil. Revista Paulista Ed. Física, São Paulo, supl. 4, p.53-60, 2001.

COLETIVO DE AUTORES. Metodologia do Ensino de Educação Física. São Paulo: Cortez, 1992.

EHRENBERG, Mônica Caldas. A dança como conhecimento a ser tratado pela Educação Física escolar: aproximações entre formação e atuação profissional. 2003. 129 fls. Dissertação Mestrado. Faculdade Educação Física, Universidade Estadual de Campinas.

- A linguagem da cultura corporal sob o olhar de professores da educação infantil. Pro-Posições, Campinas/SP, v. 25, n. 1, p. 181-198, jan./abr. 2014 EHRENBERG, Mônica Caldas; PEREZ GALLARDO, Jorge S. Dança: conhecimento a ser tratado nas aulas de Educação Física escolar. Motriz, Rio Claro/SP, v,11, n.2, p.111-116, maio/ago/2005.

FERNANDES, Rita de Cassia; BRATIFISCHE, Sandra Ap. Possibilidades pedagógicas das danças folclóricas: o gesto ressignificado nas aulas de Educação Física. In: EHRENBERG, Monica Caldas; FERNANDES, Rita de Cassia; BRATIFISCHE, Sandra Ap. Dança e Educação Física: diálogos possíveis. Varzea Paulista, SP: Fontoura, 2014

GOMES-DA-SILVA, Eliane.; SANT'AGOSTINO, Lucia H.; BETTI, Mauro. Expressão Corporal e Linguagem na Educação Física: uma perspectiva semiótica. Revista Mackenzie de Educação Física e Esporte, São Paulo, p. 29-38, 2005.

LABAN, Rudolf. Domínio do Movimento. São Paulo: Summus, 1978.

MARQUES, Isabel Azevedo. Ensino da dança hoje: textos e contextos. São Paulo: Cortez, 2001.

NEIRA, Marcos Garcia. Educação Física na Educação Infantil: algumas considerações para elaboração de um currículo coerente com a escola democrática. In: FILHO, Nelson F. A. e SCHNEIDER, Omar (org.) Educação Física 
para Educação Infantil: conhecimento e especificidade. Aracaju/SE: UFS Editora, 2008.

Educação Física na perspectiva cultural: proposições a partir do debate em torno do currículo e da expansão do Ensino Fundamental. Revista Horizontes, Itatiba/SP, v. 27, n. 2, p. 79-89, jul./dez. 2009.

Práticas Corporais - Brincadeiras, danças, lutas, esportes e ginásticas. São Paulo: Editora Melhoramentos, 2014.

SBORQUIA, Silvia P.; GALLARDO, Jorge S. P. A dança no contexto da educação física. Ijuí: Ed. Ijuí, 2006.

SIQUEIRA, Denise da Costa O. Corpo, comunicação e cultura: a dança contemporânea em cena. Campinas/SP: Autores Associados, 2006. 